\title{
無結節網地の投影面樍*i
}

今 井健应

(1984 年 3 月 15 日受理)

\section{Experimental Studies on the Projective Area of the Knotless Twisted Netting}

\section{Takehiko IMAI*2}

The purpose of this experiment is to obtain the experimental equation concerning the projective area of a twine portion on the knotless twisted netting, as the basic research for the study of the fluid dynamical coefficient at a certain attack arigle $\theta$, when the netting is set into a flow.

The netting samples used are seven kinds of knotless netting composed of varying twine diameter $d$ and leg length $l$. And the respective netting is fixed on the J-shaped netting frame at hanging angle of $45^{\circ}$, by thin stainless steel wire, while among seven, one netting is fixed at the six stages of hanging angle $\phi$.

The projective area of the twine portion is obtained from the enlarged photograph, concerning the area measured by a planimeter of one mesh which is made up of two knots and four legs forming two netting elements.

Rèsults obtained are as follows:

(1) The projective area of a twine portion on the $(i \times j)$ mesh sample, at the range of attack angle $\theta<\theta \leqq 90^{\circ}$ is calculated easily, using the following experimental equation.

$$
S_{\theta}^{\prime}=4.4 i j d l \sin \delta+(i+j-2.2 i j) \frac{d^{2}}{\sin 2 \varepsilon}+0.44 d^{2}\left(2.2 i j-\frac{i+j}{2}\right) \sin 2 \phi \sin \theta
$$

(2) The projective area, of a twine portion on the $(i \times j)$ mesh netting, at the range of attack angle $0^{\circ} \leqq \theta \leqq \theta$ is derived in the following experimental equation.

Whiere,

$$
S_{\theta^{\prime}}=0.84\left[j\left\{(2 i-1) l^{2} \sin 2 \phi \sin \theta+2 d l \sin \delta\right\}+\frac{\pi d^{2}}{4 \cos \phi}\left\{1+(i-1) \frac{\theta}{\theta}\right\}\right]
$$

$\delta$ : Angle between the leg and the horizontal plane on the ABC plane

$\varepsilon:$ Apparent hanging angle on a projected plane

$\theta$ : Attack angle

$\theta:$ Attack angle when the adjacent legs were touched on a projected plane

$S_{\theta}{ }^{\prime}: \quad$ Projective area of the twine portion of the knotless netting at attack angle $\theta<\theta \leqq 90^{\circ}$.

$S_{\theta^{\prime}}: \quad$ Upper described area of the knotless netting at attack angle $0^{\circ} \leqq \theta \leqq \theta$.

流体中を相対運動している物体が受ける流体抵抗は， ニュートンの流体抵抗則が成立するレイノルズ数の領域 では, 物体の代表面積, 流体の密度および相対運動速度 の2乗に比例することが明らがされている。流体抵抗 伱数は，比較的簡単な形状の物体についてだけ明らかに されているが，これらの場合は；相対運動方向に垂直な 面への投影面積を代表面積としている。

寺田ら゙は，絧糸が交差した投影面積を計算し，結節 投影面賸の增分を目算で加えて絧系の投影面積を求めて いる。三宅2)は，網地の見取り困から網糸投影面積を求 め，田内 ${ }^{3)}$ は網目の孔を含を 1 目の投影面積を $l^{2} \sin 2 \phi$
で表している。宮本ら ${ }^{4)}$ は, 脚数と結節数の比率は 2 奶 1 として, 脚の投影面積を $d(l-\alpha d)$, 結節の投影面積を $\beta d^{2}$ で表している。これらの場合， $d$ は網糸直径, $l$ は 脚長, $\alpha$ は結節長さの係数, $\beta$ は結節面積の係数, $\phi$ は 樎結角である。宮崎ら゙は，網地の全投影面積 $S$ 之網系 投影面積 $L d$ の比率を媒介変数として網地の流体抵抗を 解析している。この場合の $L$ は目合であり，dは網苐 直径であることから、網糸の重なり部分の倍の面積を結 節に相当する面積としている。また, H. STENGEL ${ }^{6)}$ は, ポリアミド蛙又結節網地の結節投影面積を，直径が $3 d$ の円で置きかえている。H. H. KORITZKY

*1 絧地の投影面積一 I (Experimental Studies on the Projective Area of Netting-I) 昭和 58 年度秋期大会で発表した。

*2 鹿児岛大学水産学部 漁具学請座 (Laboratory of Fishing Gear, Faculty of Fisheries, Kagoshima University Shimoarata-4, Kagoshima City 890, Japan). 
$ら^{5)}$ と同様絧系投影面積を $L d$ としている。

網地の棈造は複雑であり，加兄られた外力と釣合って 自由にその形を変える特性を持つたるに，その投影面積 の測定は繁雑であることから，徒来の絧地抵抗の研究で は，前述のように種々の面積が抵抗解析の代表面積とし て用いられてきた。本稿は，網地の投影面積の実测值に 基いた網系投影面積を求める沉用の実験式を導くことを 目的とした。

円柱を組み合わせて作製した網地模型の任意の迎角 $\theta$ における網糸投影面積の理論式を導き，その理論式と絧 地模型の写真映像から求め太絧系投影面積の実測值と比 較して理論式を実証し, 更に無結節網地のそれぞれの迎 角に打ける絧䒺投影面禎の実測值と比較して補正係数 $\lambda^{\prime}$ を導き, 理諭式と $\lambda^{\prime}$ の積を網系投影面積を求める実験 式とした。

本稿では，網地は長さ $l$ の本の網紋が，その中心で

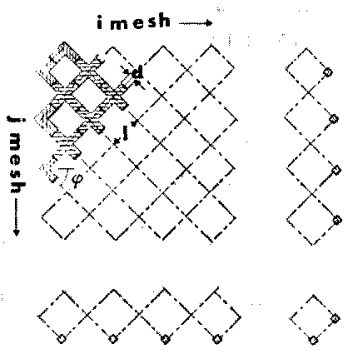

Fig. 1. Explanation of a "netting-element", the smallest construction of netting, which is composed with two legs crossed on the hanging angle, concerning a netting model. Square mark shows a remainder of the knotportion.
互いに交美している構造物（網弥子）の集合と考えてい る。従って，横目数 $i$, 繸目数 $j$ の供試網地は, Fig. 1 に示すよらに $\mathrm{x}$ 形状の $(2 i j-i-j)$ 個の完全閏素子と, $\wedge$ 形状の $2(i+j)$ 個の不完全網素子から構成されて特り， 不完全網素子 2 個の投影面積は，完全網素子 1 個之結節 部 1 個の面積に相当することから，この網地は $2 i j$ 個の 網素子と, 網地周辺の $(i+j)$ 個の結節部から構成されて いると考えた。

なお，後述の理由から，投影面上に網目の孔が現れる 迎角の範围 $\Theta<\theta \leqq 90^{\circ}$ と，投影面上に網目の孔が現れ ない迎角の籍田 $0^{\circ} \leqq \theta \leqq \theta に$ 分けて理諭式を導き，検討 を加えた。

\section{実験方 法}

供試網地は，塩化ビニル円柱を組み合わした網地模型


撚り式貫通型無結節網地である。縮結角 $\phi$ はいずれす $45^{\circ}$ であり，網地模型には支持桿を取付け，無結節䋨地 はコの字型絹枠に紐いステンレス線で㖘りつけた。な お，縮結角を变えた場合の網糸投影面積について検討す るために，網地香号林の網地について 6 段階の縮結角を 与えた実験子行った。設定迎角 $\theta$ は， $0 \sim 90^{\circ}$ の範囲の $5^{\circ}$ 毎の 19 段階である。供試網地の主要目を Table 1 に示した。

網地面の延長線上約 $10 \mathrm{~m}$ 隔たったところに望遠レン ズ (Reflex Nikkor $500 \mathrm{~mm}$ ) を装着した写真機 (Nikkon $\mathrm{F}_{3}$ ）を設直してこの場合を迎角 $0^{\circ}$ とし，網枠支持棒受 金具に取りつけた分度器で $5^{\circ}$ 毎に迎角を設定して，物 指しおよび番号札と共に網地を撮影した。夷験装置の模 式図を Fig. 2 に示した。撮影したフィルムを，文献複

Table 1. Principal dimensions of the sampled knotless nettings and netting model

\begin{tabular}{|c|c|c|c|c|c|c|}
\hline Netting & $d(\mathrm{~cm})$ & $l(\mathrm{~cm})$ & $d / l$ & $\Phi$ (deg.) & $\theta$ (deg.) & Materials \\
\hline Model & 2.10 & 6.00 & 0.350 & 45 & 13.90 & PVC round bar \\
\hline I & 0.35 & 15.00 & 0.023 & 45 & 0.95 & PVD filament \\
\hline II & 0.29 & 6.08 & 0.048 & 45 & 1.93 & PES filament \\
\hline III & 0.31 & 5.84 & 0.053 & 45 & 2.15 & PE filament \\
\hline IV & 0.39 & 6.11 & 0.064 & 45 & 2.58 & PE filament \\
\hline V & 0.09 & 1.31 & 0.069 & 45 & 2.78 & PE filament \\
\hline VI & 0.46 & 6.04 & 0.076 & 45 & 3.08 & PE filament \\
\hline VII & 0.22 & 2.50 & 0.088 & 45 & 3.56 & PE filament \\
\hline VII & 0.22 & 2.50 & 0.088 & 6.5 & 2.54 & \\
\hline VII & 0.22 & 2.50 & 0.088 & 15 & 2.61 & \\
\hline VII & 0.22 & 2.50 & 0.088 & 30 & 2.91 & \\
\hline VII & 0.22 & 2.50 & 0.088 & 60 & 5.03 & \\
\hline VII & 0.22 & 2.50 & 0.088 & 75 & 9.65 & \\
\hline D : & Hanging angle & & & & & \\
\hline $\begin{array}{l}\theta \\
\mathrm{PE}:\end{array}$ & $\begin{array}{l}\text { Attack angle when } \\
\text { Polyethylene }\end{array}$ & legs & $\begin{array}{l}\text { aed on a } \\
\text { lyester }\end{array}$ & plane & & \\
\hline PVC: & Polyvinyl chloride & & lyvinylide & & & \\
\hline
\end{tabular}




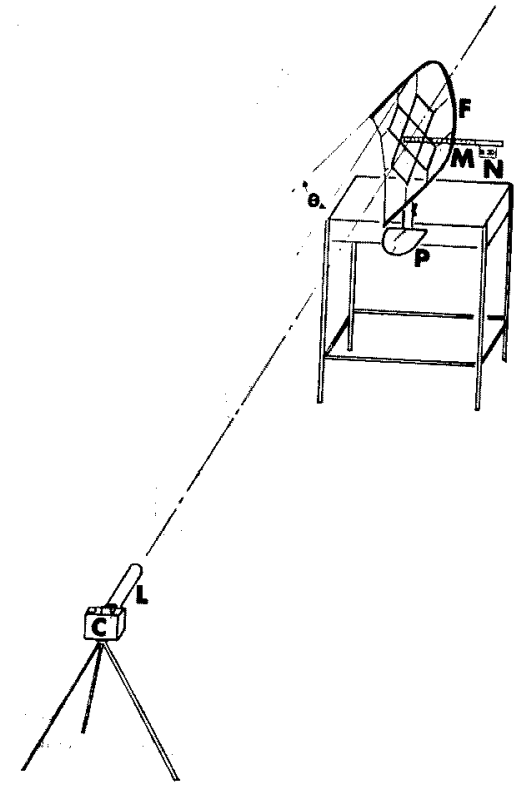

Fig. 2. Schematic drawing shows the experimental equipments.
C: Motor drive camera
N: Number plate
F: Netting frame
P: Protractor
L: $500 \mathrm{~mm}$ lens
$\theta$ : Attack angle
M: Measure

写用のマイクロリーダプリンタ(富士ゼロックス)でB 4 判に拡大複写した。投影面上に絧目の孔が現れる迎角の 範曲では，レンズの雪虽差を少なくするために，物指し 付近の网同を選び，4 脚と 2 結節部の面積をブラニメー 夕(玉㺟 Planix 7) で測定した。測定値の 1/2 を網菜 子の投影面嫧として資料処理した。一方，投影面上に網 目の孔が現れない迎角の範囲では, 供試網地全体の投影 面皘を測定した。

\section{実験結果および考察}

無結節椆地模型の棢系投影面積の理諭式と実駼式 塩 化ビニル製円柱を縮結角 $\phi$ で組み合わせた網地模型の绸 素子を任意の迎角 $\theta$ で設置した場合について検討する。 平行光源の光軸を $x$ 軸，これに直交する軸を $y$ 軸， $x-y$ 平面 (水平面) に垂直で網素子の結節部中心を通る 軸を $る$ 軸とした。 $z$ 軸は絧菜子の回転軸であり $\angle \mathrm{XOB}$ は迎角 $\theta ， \angle \mathrm{ABO}$ は縮結角 $\phi$ である。この場合の $x$ 軸 に垂直な $y-z$ 面 (投影面) 上の網素子の網糸投影面積 s。裹す理論式を(1) 式で表した。 (Fig. 3 参照)

$$
s_{\theta}=2 d l \sin \delta-\frac{d^{2}}{\sin 2 \varepsilon}
$$

但し， $d$ は䋧系直径， $l$ は脚長， $\delta$ は網素子の脚拈よ び脚の投影を含さ面上の網素子の脚と水平面の成す角

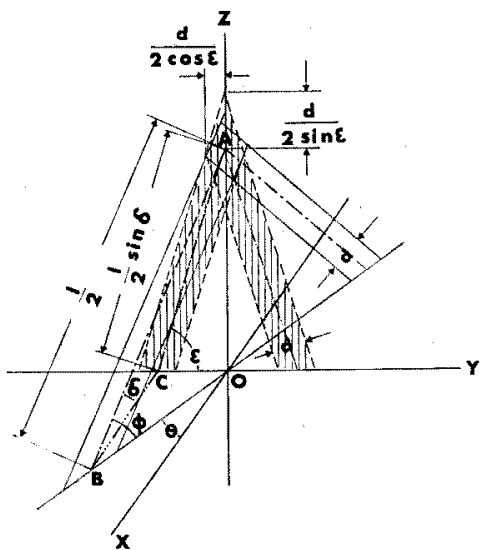

Fig. 3. Schematic drawing shows the projective area of a netting element (lower half).

$d$ : Twine diameter

$l$ : Leg length (Half mesh size)

$\delta$ : Angle between a leg and horizontal plane on the $\mathrm{ABC}$ plane

$\varepsilon$ : Apparent hanging angle on a projected plane

$\phi$ : Hanging angle

$\angle \mathrm{ABC}$ を夜して括り，(2) 式で与充られる。は投影面 上の見かけの縮結角 $\angle \mathrm{ACO}$ で (3) 式で与えられる。

$$
\begin{aligned}
& \delta=\cos ^{-1}(\cos \phi \cos \theta) \\
& \varepsilon=\sin ^{-1}(\sin \phi / \sin \delta)
\end{aligned}
$$

（1）式の第 1 項は， 2 脚の網亲投影面積であり，第 2 項は 2 脚が重なり合った部分，即ち，結節部の投影面積 である。但し，(1) 式が成立するのは，投影面上の隣接 する2 脚が互いに接する迎角 $\Theta$ より大きい範囲 $\theta<\theta \leqq$ $90^{\circ}$ であり，迎角 $\Theta$ は (4) 式で与えられる。(Fig. 4参照)

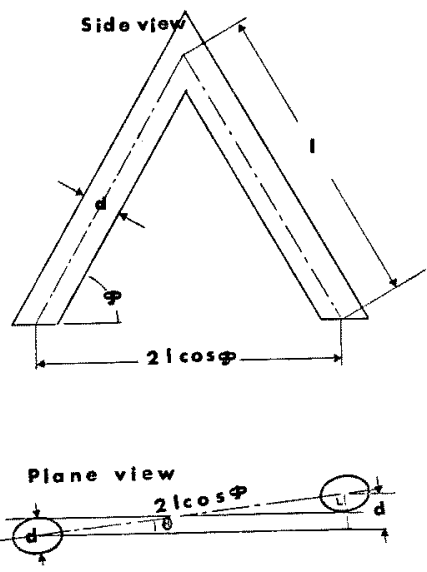

Fig. 4. Schematic drawing shows the attack angle $\theta$, when the adjacent legs were touched on a projected plane. 


$$
\theta=\tan ^{-1}\left(\frac{d}{2 l \cos \phi}\right)
$$

網目数かi $i \times j$ 目の網地の網素子数は，前迹のように $2 i j$ 個の網素子と, 網地周辺の $i+j$ 個の結節から構成 されているので，その網系投影面積 $S_{\theta}$ は (5) 式となる。

$$
S_{\theta}=4 i j d l \sin \delta+(i+j-2 i j) \frac{d^{2}}{\sin 2 \varepsilon}
$$

前述の方法で無結節網地模型の各迎角における網等子 の網系投影面積 $s_{6 \mathrm{~m}}$ を測定し，供試網地模型に換算し た網地の絧亲投影面積の実测值 $S_{\theta \mathrm{m}}$ と (5) 式で求めた同 計算值 $S_{\theta}$ の関保を Fig. 5 に示した。両者の関保を表 す回帰直線式を最小自乗法で求め (6) 式を得た。

$$
S_{\theta m}=1.025 S_{\theta} \doteqdot S_{\theta}
$$

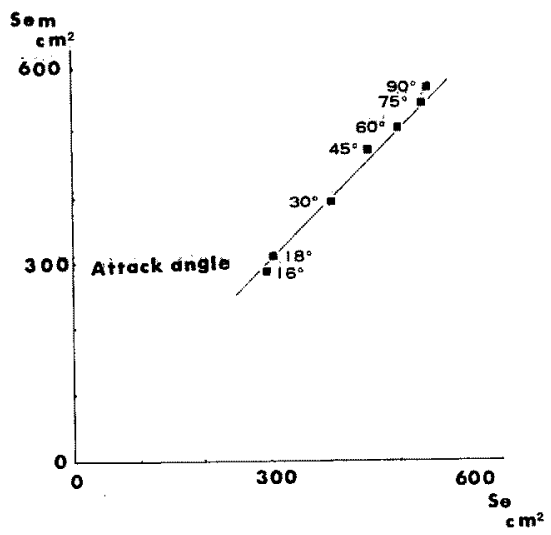

Fig. 5. Relationship between the calculated projective area of a netting model, using the equation (5), and measured one at the range of attack angle $\theta<\theta \leqq 90^{\circ}$. Line shows the result of the calculation on a linear regression, and number shows attack angle.

導いた理論式は，実測值と良く一致した。

投影面上に網目の孔が現れない場合，即 b，迎角が $0^{\circ} \leqq \theta \leqq \theta$ の簐囲について，絧目数が $i \times j$ 目の無結節網 地の網系投影面積の理論式を(7) 式で表した。 (Fig. 6 . 参照)

$$
\begin{aligned}
S_{\theta t}= & \left.\{2 i j-i-j+1) 2 l^{2} \sin \phi \cos \phi \sin \theta\right\} \\
& +\left\{2 j(d l \sin \delta)+\frac{\pi d^{2}}{4 \cos \phi}\right\} \\
& +\left\{(i-1)\left(2 l^{2} \sin \phi \cos \phi \sin \theta\right)\right. \\
& \left.+\frac{\pi \mathrm{d}^{2}}{4 \cos \phi} \frac{\theta}{\Theta}\right\}
\end{aligned}
$$

（7）式の右辺第 1 項は，網地模型を平面と仮定した 菱形状の面積 (横縞)，第 2 項は，前端の脚の面積（斜 縞）であり，第 3 項は上下端の三角状の卦と，半棈円形 状の前の結節部に隐れる結節部面積 (狳縞) を表してい る。この場合結節部の遮蔽率を $\theta / \Theta$ と仮定している。



Fig. 6. Schematic drawing shows projective area on the knotless netting model, at the attack angle $\theta=\theta, \theta<\theta$, and $\theta=0^{\circ}$.

(7) 式を整理すると，(8) 式学得る。

$$
\begin{aligned}
S_{\theta t}= & j\left\{(2 i-1) l^{2} \sin 2 \phi \sin \theta+2 d l \sin \delta\right\} \\
& +\frac{\pi d^{2}}{4 \cos \phi}\left\{1+(i-1) \frac{\theta}{\theta}\right\}
\end{aligned}
$$

な找， $\theta=0^{\circ}$ の場合は，(8) 式は次式となる。

$$
\begin{gathered}
S_{(0)}=2 j d l \sin \phi+\frac{\pi d^{2}}{4 \cos \phi} \\
\because \quad \cos \delta=\cos \phi \cos \theta \\
\theta=0^{\circ} \rightarrow \delta=\phi
\end{gathered}
$$



Fig. 7. Relationship between the calculated projective area of a netting model using the equation (8), and measured one at the range of attack angle $0^{\circ} \leqq \theta \leqq \theta$. Line shows the result of the calculation on a linear regtession, and number shows the attack angle. 
前速の方法で測定した網地模型の網系投影面積の夷測 值 $S_{\theta_{m}}$ と(8) 式で求めた同計算值 $S_{\theta}$ 関係を Fig. 7 に 示した。両者の凰系を表す回帰直線式を最小自乗法で求 め，(9) 式を得た。

$$
S_{\theta m}=0.988 S_{\theta} \risingdotseq S_{\theta}
$$

これらの結果, 迎角が $\theta$ より小さな場合について導い た理論式 (8) 式は，実験值と良く一致した。即ら，(5) および (8) 式は種々の城地の網糸投影面積の実験式を導 くための基碄方程式として用いることができることが明 らかとなった。

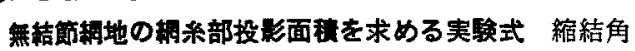

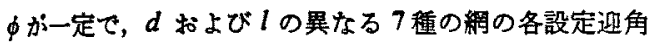
が $\theta$ より大きい場合の網素子の網采投影面積之，絧地番 号UI網地の縮結を6 段階变えた場合の同投影面皘をプ ラニタータで测定した。

無結節網地の結節部は，円柱を組み合わした網地椦型 の結節部と形状が異なっており，Fig. 8 に示すよ5に 若干広い投影面積を持っている。相対運動方向に垂直に 設置された結節部 1 個の投影面積の増分 $A s^{\prime} k$ を(10) 式 で表した。

$$
\Delta s^{\prime} k=4 \eta^{2} \sin \phi \cos \phi=2 r^{2} \sin 2 \phi
$$

$\phi=45^{\circ}, \theta=90^{\circ}$ の場合の結節部払大写真映像の $2 \eta \sin \phi$ の長さを各網地について測定して，網系面径との関係を 求め $0.66 \mathrm{~d}$ を得た。即ち、クは (11) 式で与克られる。

$$
\eta=\frac{0.33 d}{\sin 45^{\circ}}=0.468 d
$$

$\Delta s^{\prime} k$ は網素子の投影面積 $s^{\prime}{ }_{\theta}$ に比へ微少であること から, $\theta$ の变化に対応する $\Delta s^{\prime} k$ の面積の変化量を



Fig. 8. Schematic drawing shows a crossing portion on the diagonal through type knotless twisted netting.

$\eta$ : Length of a ply along the crossing portion (knot) of an above mentioned netting.
式で表すことができるものと仮定した。即ち，片子糸の 太さを無視して, 結節部の投影面積の增分は平面と仮定 した。

$$
\Delta s^{\prime} k=0.44 d^{2} \sin 2 \phi \sin \theta
$$

これらの結果から，無結節網素子の網乐部投影面積 $s_{\theta t}^{\prime}$ を求める理論式は，(5) 式と (12) 式の和として (13) 式で与えられる。

$$
\begin{gathered}
s_{\theta t}^{\prime}=2 d l \sin \delta-\frac{d^{2}}{\sin 2 \varepsilon}+0.44 d^{2} \sin 2 \phi \sin \theta \\
d, l \text { が果なり, } \phi=45^{\circ} の 7 \text { 種の無結節網地の } \theta<\theta \leqq
\end{gathered}
$$
$90^{\circ}$ の迎角の範囲について，網素子の網糸投影面積の実 測值と（13）式の同計算值を比較して，補正係数 $\lambda_{\theta}^{\prime}=$ 1.099 を得た。従って，この場合の網系投影面積の害験 式は (14) 式と $\chi_{\theta}^{\prime}$ の積となる。

$$
s_{\theta}^{\prime}=1.1\left\{2 d l \sin \delta-\frac{d^{2}}{\sin 2 \varepsilon}+0.44 d^{2} \sin 2 \phi \sin \theta\right\}
$$

一方，網地番号 VII の縮結角を変えた場合についても （14）式は成立した。従って，迎角が $\Theta$ より大きい場合 の全ての資料について，網素子の網系投影面積の実測值 $s_{\theta m}^{\prime}$ と(15) 式の関係を調べ，Fig. 9 に示した。この場 合補正俰数は $\lambda^{\prime}{ }_{\theta}=1.106$ であり，両者の相関係数は 0.983 , 自由度 107 に和る $t$ 検定の結果, 0.01 水準て 有意であった。これらの結果から，網目数が $i \times j$ 目の 供試絧地の投影面積を求める実験式は (15) 式で与えら れる。

$$
\begin{aligned}
S_{\theta}^{\prime}= & 4.4 i j d l \sin \delta+(i+j-2.2 i j) \frac{d^{2}}{\sin 2 \varepsilon} \\
& +0.44 d^{2}\left(2.2 i j-\frac{i+j}{2}\right) \sin 2 \phi \sin \theta
\end{aligned}
$$



Fig. 9. Relationship between the calculated projective area of the knotless netting element, using the equation (14), and the measured one at the range of attack angle $\theta<\theta \leqq 90^{\circ}$. 




Fig. 10. Relationship between the calculated projective area of knotless netting, using the equation (16), and the measured one at the range of attack angle $0^{\circ}<\theta \leqq \theta$.

投影面上に網目の孔が現れない迎角の範国 $0^{\circ} \leqq \theta \leqq \theta$ についても，浪同様な方法で資料処理した。この昜合 結節部の增分 $4 s_{k \theta}^{\prime}$ は脚の投影と重なり合らので考虑す る必要はない。従って，(8) 武と実測值を比較して，画 者の関俰を回㷌直線式で求め, 補正係数 $\lambda_{\theta}{ }^{\prime}=0.837$ を得

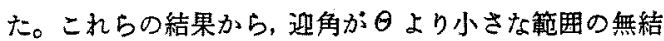
節網地の絧来部投影面積を求める実験式は(8)式と $\lambda_{\theta}$ の 積として (16) 式で与えられる。

$$
\begin{aligned}
S_{\theta}^{\prime}= & 0.84\left[j\left\{(2 i-1) l^{2} \sin 2 \phi \sin \theta+2 d l \sin \hat{o}\right\}\right. \\
& \left.+\frac{\pi d^{2}}{4 \cos \phi}\left\{1+(i-1) \frac{\theta}{\theta}\right\}\right]
\end{aligned}
$$

なお， $\theta=0^{\circ}$ の場合については次式となる。

$$
S_{(0)}^{\prime}=0.84\left(2 j d l \sin \phi+\frac{\pi d^{2}}{4 \cos \phi}\right)
$$

網糸投影面積の実測值 $S_{\theta m}^{\prime}$ 之, 導いた (16) 式の計 算值 $S_{\theta}{ }^{\prime}$ の関係を Fig. 10 K示した。両者の相関保数 は 0.960 であり，自由度 $66 に お い て ~ t$ 検定を行った結 果 0.01 水準で有意であった。

導いた実験式（15）および (16) 式は，いずれる実験 值と良く一致した。これらの実験式をプログラムに組む ことにより，任意の無結節網地の，任意の姿勢について の網禾投影面積を容易に得ることができ，ひいては網地 が受ける流体抵抗の抵抗係数の精度を上げることができ る。

この研究は，北海道大学水産学部教授佐藤修博士なら びに本講座教授肥後伸夫博士の御指導の下に，大学院生 吉賀窅二君，学生住吉誠君の協力を得て行った。ここに 記し、深甚の暗意を表します。

文 献

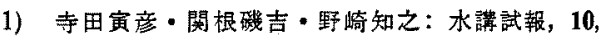
1-23 (1915).

2) 三宅 豊：水䧿試報，23，48-61 (1927).

3) M. Tautr: Bull. Japan. Soc. Sci. Fish, 3, 171-177 (1934)

4) 宫本秀明 - 野村正恒 -下崎吉矩：日水誌，17, 39-43 (1952).

5）宮崎芳夫・高榙 正：Jorn. Tokyo Univ. Fish, 50, 95-102 (1964)

6) H. STENGEL and A. FisCher: Fischerei Forschung, 6, 45-59 (1963)

7) H. H. KoRITZKY: Fischerei Forschung, 8, 4146 (1970) 